\title{
Alexithymia and its association with burnout, depression and family support among Greek nursing staff
} Dionisios Bratis*1, Athanasios Tselebis ${ }^{1}$, Christos Sikaras ${ }^{1}$, Aikaterini Moulou ${ }^{1}$, Konstantinos Giotakis ${ }^{1}$, Emmanuel Zoumakis ${ }^{2}$ and Ioannis Ilias ${ }^{3}$

\author{
Address: ${ }^{1}$ Sotiria General Hospital of Chest Diseases, Athens, Greece, ${ }^{2}$ First Department of Pediatrics, University of Athens Medical School, Athens, \\ Greece and ${ }^{3}$ Endocrine Department, Elena Venizelou Hospital, Athens, Greece \\ Email: Dionisios Bratis* - dionbratis@yahoo.gr; Athanasios Tselebis - atselebis@yahoo.gr; Christos Sikaras - cris.sikaras@gmail.com; \\ Aikaterini Moulou - aikmoulou@yahoo.gr; Konstantinos Giotakis - kgiotakis@gmail.com; Emmanuel Zoumakis - zoumakis@bioacademy.gr; \\ Ioannis Ilias - iiliasmd@yahoo.com \\ * Corresponding author
}

Published: II August 2009

Human Resources for Health 2009, 7:72 doi:10.1186/1478-449|-7-72
Received: 18 March 2009

Accepted: II August 2009

This article is available from: http://www.human-resources-health.com/content/7/I/72

(c) 2009 Bratis et al; licensee BioMed Central Ltd.

This is an Open Access article distributed under the terms of the Creative Commons Attribution License (http://creativecommons.org/licenses/by/2.0), which permits unrestricted use, distribution, and reproduction in any medium, provided the original work is properly cited.

\begin{abstract}
Background: Few studies have examined the relation between alexithymia (i.e. the inability to recognize and verbalize emotions) and professional burnout. Considering the absence of relevant studies in the Greek scientific literature, the aim of this work was to examine the associations of alexithymia with the three facets of professional burnout, the perception of family support and depression in nursing personnel.
\end{abstract}

Methods: The study was performed in one of the largest hospitals in Greece and included 95 nurses. Assessments of alexithymia, burnout, depression and family support were made by means of the Toronto Alexithymia Scale, the Maslach Burnout Inventory, the Beck Depression Inventory and the Julkunen Family Support Scale, respectively. Student's t-test, Pearson's correlation and stepwise linear regression were used for the evaluation of data.

Results: Alexithymia was correlated positively with depression, emotional exhaustion and depersonalization, and negatively with sense of family support and personal achievement. Additionally, family support was correlated positively with personal achievement and negatively with depression.

Conclusion: In the scientific literature there is a debate as to whether alexithymia is a stable personality characteristic or if it is dependent on symptoms of mental disorders. We tried to interpret the associations of alexithymia with professional burnout, depressive symptoms and family support. From this study it appears very likely that alexithymia is directly associated with depression and personal achievement, but also indirectly with the sense of family support. 


\section{Background}

Sifneos introduced the notion of alexithymia as the inability to recognize and verbalize emotions $[1,2]$. Newer studies on alexithymia defined it as weakness in the determination and expression of emotions; moreover, alexithymia encompasses externally directed thought and limited imaginative faculty [3].

Alexithymia appears to be positively associated with depression in the general population [4] and has been shown to be associated with several diseases [5]; in characteristically alexithymic subjects the favourable effect of family and social support on depressive symptomatology is diminished $[6,7]$. Alexithymia is conceptualized as a stable personality trait; some studies have associated it with psychopathological disorders (such as depression or anxiety) or with somatic diseases [8].

The notion of professional burnout was introduced by Freudenberger, who described overstrain symptoms that he observed in professionals and volunteers in the mental health sector [9]. The most widely accepted definition of burnout was formulated by Maslach, who described it as a mental syndrome (along with bodily exhaustion) that develops in people who have a professional relationship with other persons [10]: the worker loses the interest and positive sentiments that he/she had for patients or customers and develops a negative self-image.

Depression, which is common in mental health workers compared with the general population [11] in a number of reports, is correlated positively with professional burnout $[12,13]$.

Family support refers to the sense of support that an individual perceives he or she receives from his or her familial environment; it constitutes an important element of social support, particularly in the Greek population, with its close-knit families [14]. The positive effect of family support becomes particularly obvious in patients with chronic diseases, as in the case of diabetes [14,15]. Research stresses the negative cross-correlation that is observed between family support and depression [6], while a recent study reports the existence of negative crosscorrelation between family support and professional burnout [16].

Few studies have examined the relationship between alexithymia and professional burnout $[17,18]$. The findings suggest that alexithymia is significantly associated with burnout even when controlled for confounding factors [18].

Considering the absence of relevant studies in the Greek scientific literature, the aim of this work was to examine the associations of alexithymia with professional burnout, the perception of family support and depression in nursing personnel.

\section{Methods}

The study was performed in one of the largest hospitals in Greece. Eighteen men and 82 women of the hospital's nursing staff of 670 were selected randomly; 17 men and 78 women agreed to participate. Mean age \pm SD was 36.7 \pm 6.5 years, with mean work experience $12.9 \pm 6.7$ years (Table 1). The nurses were asked to give answers to questionnaires for professional burnout, depression, alexithymia and sense of family support; all the subjects did so within 20 minutes at most.

Alexithymia was assessed with the 20-item self-answered Toronto Alexithymia Scale (TAS-20) [19-21]. Each item is

Table I: Descriptive statistics

\begin{tabular}{|c|c|c|c|c|c|}
\hline & $\mathbf{N}$ & Minimum & Maximum & Mean & Std. Deviation \\
\hline Age & 95 & 21 & 55 & 36,612 & 6,760 \\
\hline Work experience (years) & 95 & 1 & 31 & 12,893 & 6,927 \\
\hline BDI (Depression) & 95 & 0 & 33 & 8,473 & 6,573 \\
\hline FS (Family support) & 95 & 28 & 65 & 47,708 & 9,468 \\
\hline TAS (Alexithymia) & 95 & 20 & 81 & 46,842 & 13,375 \\
\hline E.E (Emotional exhaustion) & 95 & 6 & 52 & 26,336 & 11,655 \\
\hline SPA (Sense of personal accomplishment) & 95 & 7 & 48 & 33,778 & 8,511 \\
\hline DEP (Depersonalization) & 95 & 0 & 26 & $|0,83|$ & 6,365 \\
\hline
\end{tabular}


rated from 1 to 5 . The questionnaire's translation into modern Greek had good reliability (alpha $=0.80)$. Scores $>60$ indicate alexithymic characteristics [1]. The TAS-20 consists of three factor scales: Difficulty Identifying Feelings (DIF), Difficulty Describing Feelings (DDF) and Externally Oriented Thinking (EOT). The scale includes five negatively keyed items (items 4, 5, 10, 18 and 19).

To measure professional burnout we used Maslach's 22item Burnout Inventory (MBI), which assesses emotional exhaustion (for evaluation of the frequency of emotional stress due to work), depersonalization (that reflects reactions of indifference and impersonal handling of patients) and the lack of personal achievement (that measures the sense of sufficiency, efficiency and achievements in the professional sector). Each item was answered on a scale from 0 (never) to 6 (every day). The questionnaire was translated into modern Greek and validated with Greek nurses; emotional exhaustion is associated with values higher than 30, depersonalization is associated with levels higher than 11 and lack of personal achievement with values higher than 35, in the relevant subscales [22].

For depression, Beck's Depression Inventory (BDI) was used. It assesses depression through answers in 21 items (rated on a scale from 0 to 3 ) [23,24]. Its internal validity is high and its test-retest reliability is 0.480 .86 for clinical and 0.600.90 for non-clinical subjects, respectively. External validity vis-à-vis a clinical diagnosis of depression is considered to be satisfactory; scores $\geq 14$ indicate moderate to severe depression.

To measure perception of family support we used, as in previous studies, Julkunen's 13-item questionnaire $[6,15,25,26]$. All 13 items of the scale (e.g. item 1: "My family supports me in all my efforts" and item 5: "I am always the one to blame when our home is a mess") are rated on a five-point scale; scores > 37 indicate an increased sense of family support. The questionnaire's adaptation in modern Greek presented good reliability (alpha $=0.80$ ). Individuals living by themselves (16 of the total sample) did not answer the questionnaire.

Student's t-test, Pearson's correlation and stepwise linear regression were used for the evaluation of data. Two-tailed statistical significance was set at $\mathrm{p} \leq 0.05$. The computations were carried out with SPSS for Windows, version 15.0 , statistical software.

The study was briefly explained to the participants. The confidentiality of the participants' answers was guaranteed. No financial support was necessary.

Table 2: Means and differences in BDI, FS, TAS and MBI dimensions between genders

\begin{tabular}{|c|c|c|c|c|c|}
\hline & & $\mathbf{N}$ & Mean & Std. Deviation & Std. Error \\
\hline \multirow[t]{2}{*}{ BDI (Depression) } & MALE & 17 & $6,53^{*}$ & 4,32 & 0,105 \\
\hline & FEMALE & 78 & $8,90 *$ & 6,92 & 0,780 \\
\hline \multirow[t]{2}{*}{ FS (family support) } & MALE & 15 & $52,80^{* *}$ & 8,04 & 2,07 \\
\hline & FEMALE & 64 & $46,52^{* *}$ & 9,43 & 1,18 \\
\hline \multirow[t]{2}{*}{ TAS (alexithymia) } & MALE & 17 & $41,00^{*}$ & 12,06 & 2,92 \\
\hline & FEMALE & 78 & $48,12^{*}$ & 13,38 & 1,51 \\
\hline \multirow[t]{2}{*}{ E.E (Emotional exhaustion) } & MALE & 17 & 28,71 & $|3,2|$ & 3,20 \\
\hline & FEMALE & 78 & 25,82 & $|I, 3|$ & 1,28 \\
\hline \multirow[t]{2}{*}{ SPA (Sense of personal accomplishment) } & MALE & 17 & $36,58^{*}$ & 6,56 & 1,59 \\
\hline & FEMALE & 78 & $33,17^{*}$ & 8,80 & 0,997 \\
\hline \multirow[t]{2}{*}{ DEP (Depersonalization) } & MALE & 17 & 11,12 & 7,17 & $\mathrm{I}, 74$ \\
\hline & FEMALE & 78 & 10,77 & 6,22 & 0,70 \\
\hline
\end{tabular}

$* \mathrm{~T}$ test $\mathrm{p}<0.05, * * \mathrm{~T}$ test $\mathrm{p}<0.01$ 
Table 3: Pearson correlations

\begin{tabular}{llllll}
\hline & & TAS & SE & SPA & DEP \\
\cline { 2 - 6 } Pearson correlation Sig. (2-tailed) N $=95$ & SE & $0,361^{* *}$ & & \\
\cline { 2 - 6 } & & EPE & $-0,415^{* *}$ & $-0,332^{* *}$ & \\
\cline { 2 - 6 } & AP & $0,346^{* *}$ & $0,493^{* *}$ & $-0,404^{* *}$ \\
\cline { 2 - 6 } & BDI & $0,514^{* *}$ & $0,482^{* *}$ & $-0,303^{* *}$ & $0,367^{* *}$ \\
\hline
\end{tabular}

$*_{p}<0.05, *_{p}<0.01$

\section{Results}

All distributions of the continuous variables were normal (One-Sample Kolmogorov-Smirnov Test, p > 0.05).

No statistically significant difference was noted between men and women regarding age (men $35.06 \pm 3.27$ versus women $37.03 \pm 7.39$ years, t-test $\mathrm{p}>0.05)$; women, however, had more work experience compared with men (men $8.06 \pm 4.16$ versus women $13.96 \pm 6.98$ years, t-test $\mathrm{p}<0.01)$. The questionnaires' scores did not correlate with age; work experience was correlated with BDI scores (Pearson correlation $\mathrm{p}<0.05$ ). This correlation disappeared after controlling for age (partial correlation $\mathrm{p}>$ $0.05)$.

Moderate to severe depressive symptoms, with BDI scores $>14$ were found in $16.8 \%$ of subjects. Alexithymic characteristics, with TAS scores $>60$ were noted in $14.7 \%$ of subjects, whereas low sense of family support was seen in $15.2 \%$ of them. Regarding professional burnout, emotional exhaustion, depersonalization and lack of personal achievement were noted in $38.9 \%, 46.3 \%$ and $49.5 \%$ of subjects, respectively; only $14.7 \%$ of them had pathological scores in all subscales. Women had higher BDI and TAS-20 scores compared with men (t-test $\mathrm{p}<0.05$ ). Women had lower scores than men in the personal

Table 4: Partial correlations

\begin{tabular}{|c|c|c|c|c|c|}
\hline & & SE & SPA & DEP & BDI \\
\hline \multirow[t]{4}{*}{ Partial Correlation Controlling For Alexithymia (TAS) } & EPE & $-0,119$ & & & \\
\hline & $\mathrm{AP}$ & $0,442^{*}$ & $-0,238 * *$ & & \\
\hline & BDI & $0,414^{* *}$ & $-0,168$ & $0,250 *$ & \\
\hline & FS & $-0,001$ & 0,184 & 0,104 & $-0,116$ \\
\hline
\end{tabular}

$*_{\mathrm{p}}<0.05, *_{\mathrm{p}}<0.01$ achievement subscale of MBI (t-test p < 0.05), as well as in their perception of family support (Table 2 ).

Alexithymia was correlated positively with depression, emotional exhaustion and depersonalization and negatively with sense of family support and personal achievement (Table 3). Family support was correlated positively with personal achievement and negatively with depression (Table 3). Controlling for alexithymia, these correlations did not reach statistical significance (Table 4).

Stepwise linear regression showed that 28.9\% and $12.2 \%$ of depression values were attributed to alexithymia and emotional exhaustion, respectively. Alexithymia accounted for $24.7 \%$ of family support values. Emotional exhaustion was accounted-for mostly by depersonalization $(27 \%)$ and depression (11.5\%). Emotional exhaustion was attributed to $27 \%$ of depersonalization; the latter was attributed at $6.2 \%$ to personal achievement. Personal achievement was attributed to alexithymia (23.6\%) and to depersonalization (4.3\%).

\section{Discussion}

There is an ongoing scientific debate regarding the stable or dependent characteristics of alexithymic symptoms, particularly vis-à-vis the relationship between alexithymia and depression $[8,18]$. Our results lend credence to the 
relationship between alexithymia and depression, without looking into the above-mentioned debate, which is beyond this study's scope.

Additionally, our findings are in accordance to a previous study [18], which concluded that both alexithymia and depression are associated with burnout, even though they suggest that alexithymia may be an independent risk factor for burnout. Furthermore, it seems that subjects with depressive characteristics show increased vulnerability to burnout because of their innate lack of ability to derive satisfaction from their work [13].

That family support correlates positively with personal achievement is in accordance with previous studies [13]. In these studies, it appeared that increased engagement in family support acts protectively against the development of burnout. On the other hand, it seems possible that individuals with alexithymic characteristics might be unable to benefit from their family support.

This study has limitations; in particular, the workplace conditions per se were not quantified or included in the study's parameters. The inclusion of such parameters is warranted in further studies.

\section{Conclusion}

We tried to interpret the associations of alexithymia with professional burnout, depressive symptoms and family support. Alexithymia was directly associated with depression and personal achievement, but also indirectly with the sense of family support.

Although we did not evaluate the effect of specific interventions (such as support groups or family therapy techniques) in individuals with overtly alexithymic characteristics, we believe that alexithymia should be taken into account in interventions targeting depression and/or burnout.

\section{Competing interests}

The authors declare that they have no competing interests.

\section{Authors' contributions}

DB and AT conceived the paper, carried out the mathematical analysis and drafted the paper; CS, AM and KG performed the clinical measurements, collected data and helped draft the manuscript; EZ carried out the mathematical analysis; II conceived the paper, carried out the mathematical analysis and helped draft the paper. All authors read and approved the final manuscript.

\section{References}

I. Sifneos PM: Short- term Psychotherapy and Emotional Crisis Cambridge, MA: Harvard University Press; 1972.
2. Luminet D: Alexithymia. A new syndrome? Acta Psychiatr Belg 1983, 83:289-294.

3. Lumley MA, Neely LC, Burger AJ: The assessment of alexithymia in medical settings: implications for understanding and treating health problems. J Pers Assess 2007, 89:230-246.

4. Honkalampi K, Hintikka J, Tanskanen A, Lehtonen J, Viinamaki H: Depression is strongly associated with alexithymia in the general population. Journal of Psychosomatic Research 2000, 48:99-104.

5. Karkanias A, Moussas G, Stamouli D, Tselebis A, Bakogianni T: Alexithymia, anxiety and depression in patients with bronchial asthma. European Neuropsychopharmacology 2003, I3(suppl 4):S 464.

6. Tselebis A, llias I, Moulou A, Bratis D: Depression, family support and alexithymia in patients with bronchial asthma. Annals of General Psychiatry 2005, 4(suppI I):S I28.

7. Kojima M, Senda Y, Nagaya T, Tokudome S, Furukawa TA: Alexithymia, depression and social support among Japanese workers. Psychotherapy and Psychosomatics 2003, 72:307-3I4.

8. Sanchez FM, Garcia MA, Soria BO: Alexithymia State or Trait? The Spanish Journal of Psychology 2003, 6:5I-59.

9. Roberts GA: Burnout: psychobabble or valuable concept? $\mathrm{Br} J$ Hosp Med 1986, 36:194-197.

10. Maslach C: Burnout: The cost of caring Upper Saddle River, NJ: Prentice Hall; 1982.

II. Tselebis A, Gournas G, Tzitzanidou G, Panaghiotou A, llias I: Anxiety and Depression in Greek nursing and medical personnel. Psychological Reports 2006 2006, 99:93-96.

12. Tselebis A, Moulou A, llias I: Burnout versus depression and sense of coherence: Study of Greek nursing staff. Nursing and Health Sciences 200I, 3:69-7I.

13. Tselebis A, Bratis D, llias I: Depression in women physicians and nurses: a view from Athens, Greece. In Women and Depression Edited by: Hernandez P, Alonso S. Hauppauge, NY: Nova Publishers in press.

14. Ilias I, Hatzimichelakis E, Souvatzoglou A, Anagnostopoulou T, Tselebis A: Perception of family support is correlated with glycemic control in Greeks with diabetes mellitus. Psychological Reports 2001, 88:929-930.

15. Ilias I, Tselebis A, Theotoka I, Hatzimichelakis E: Association of perceived family support through glycemic control in native Greek patients managing diabetes with diet alone. Ethnicity and Disease 2004, 14:2.

16. Tselebis A, Bratis D, Karkanias A, Apostolopoulou E, Moussas G, Gournas G, llias I: Associations of burnout dimensions and family support for a sample of Greek nurses. Psychological Reports 2008, 103:63-66.

17. de Vente W, Kamphuis JH, Emmelkamp PM: Alexithymia, risk factor or consequence of work related stress? Psychother Psychosom 2006, 75:304-3II.

18. Mattila AK, Ahola K, Honkonen T, Salminen JK, Huhtala H, Joukamaa $\mathrm{M}$ : Alexithymia and occupational burnout are strongly associated in working population. Journal of Psychosomatic Research 2007, 62:657-665.

19. Bagby RM, Parker JD, Taylor GJ: The twenty item Toronto Alexithymia Scale I. Item selection and cross-validation of the factor structure. J Psychosom Res 1994, 38:23-32.

20. Bagby RM, Taylor GJ, Parker JD: The twenty item Toronto Alexithymia Scale II. Convergent, discriminant and concurrent validity. J Psychosom Res 1994, 38:33-40.

21. Anagnostopoulou T, Kioseoglou G: The Toronto Alexithymia Scale TAS 20 [in modern Greek]. In Psychometric tools in Greece Edited by: Stalikas A, Triliva S, Roussi P. Athens, Greece: Ellinika Grammata; 2000:100-101.

22. Anagnostopoulos F, Papadatou D: Factorial composition and internal consistency of the Greek version of the Maslach Burnout Inventory demonstrated in a sample of nurses [in Greek]. Psychologika Themata 1992, 5:183-202.

23. Beck AT, Steer RA: Manual for the revised Beck Depression Inventory San Antonio, TX: Psychological Corporation; 1987.

24. Donias S, Demertzis I: Validation of the Beck Depression Inventory [in Greek]. In 10th Hellenic Congress of Neurology and Psychiatry: 1983; Thessaloniki, Greece University Studio Press; 1983:486-492.

25. Julkunen J, Greenglass ER: The Family Support Scale Ontario, Canada: York University; 1989. 
26. Tselebis A, Bratis D, Moussas G, Karkanias A, Tzitzanidou G, Lekka $D$, Papageorgiou E, Ilias I: Study of anxiety, family support and type A behavior in patients with cardiovascular disease. 27th Conference of the STAR Society: 2007 2007:196-20I.

Publish with Bio Med Central and every scientist can read your work free of charge

"BioMed Central will be the most significant development for disseminating the results of biomedical research in our lifetime. " Sir Paul Nurse, Cancer Research UK

Your research papers will be:

- available free of charge to the entire biomedical community

- peer reviewed and published immediately upon acceptance

- cited in PubMed and archived on PubMed Central

- yours - you keep the copyright

Submit your manuscript here:

http://www.biomedcentral.com/info/publishing_adv.asp 